\title{
Patients with Chronic Hepatitis C May be More Sensitive to Iron Hepatotoxicity than Patients with HFE-Hemochromatosis
}

\author{
Hisao Hayashi ${ }^{1}$, Alberto Piperno ${ }^{2}$, Naohisa Tomosugi ${ }^{3}$, Kazuhiko Hayashi ${ }^{4}$, \\ Fumiaki Kimura $^{5}$, Shinya Wakusawa ${ }^{6}$, Motoyoshi Yano ${ }^{7}$, Yasuaki Tatsumi ${ }^{1}$, Ai Hattori ${ }^{1}$, \\ Sara Pelucchi ${ }^{2}$, Yoshiaki Katano ${ }^{4}$ and Hidemi Goto ${ }^{4}$
}

\begin{abstract}
Aim In chronic hepatitis $\mathrm{C}$, iron might play an important role as a hepatotoxic co-factor. Therefore, venesection, a standard treatment for hemochromatosis, has been proposed as an alternative for patients who respond poorly to anti-viral therapy. To improve our understanding of iron-induced hepatotoxicity, we compared the responses to venesection between patients with chronic hepatitis $\mathrm{C}$ and those with HFEhemochromatosis.

Methods Fourteen Japanese patients with chronic hepatitis $\mathrm{C}$ and eight Italian patients with HFEhemochromatosis underwent repeated venesection with a serum ferritin endpoint of 20 and $50 \mathrm{ng} / \mathrm{mL}$, respectively. Serum iron indices and liver function tests were measured in pre- and post treatment blood samples from each patient. Body iron stores were calculated using the removed blood volume.

Results In both patients with hepatitis and hemochromatosis, serum ferritin, aminotransferase and hepcidin 25 were reduced after venesection. The serum aminotransferase activity, but not the serum ferritin level, was predictive of effective iron removal treatment. Hepcidin regulation was set at an inappropriately low level in hemochromatosis patients $(11.1 \pm 9.2 \mathrm{ng} / \mathrm{mL})$, but not so in hepatitis patients $(30.7 \pm 14.5 \mathrm{ng} / \mathrm{mL})$. Inversely, the estimated body iron stores of hemochromatosis patients were 5,960 $\pm 2,750 \mathrm{mg}$, while those of hepatitis patients were $730 \pm 560 \mathrm{mg}$. Judging from the liver enzyme reduction ratio, patients with hepatitis seemed to be more sensitive to iron hepatotoxicity than hemochromatosis patients.

Conclusion Even though the threshold of iron hepatotoxicity and benefit of its removal differ between patients with chronic hepatitis $\mathrm{C}$ and those with HFE-hemochromatosis, venesection is a valid choice of treatment to reduce liver disease activity in both diseases.
\end{abstract}

Key words: body iron store, hemochromatosis, HFE, hepatitis C, hepcidin, venesection

(Intern Med 49: 2371-2377, 2010)

(DOI: 10.2169/internalmedicine.49.4088)

\section{Introduction}

A door to genetic diagnosis of hereditary hemochromasis was opened in 1996 by Feder et al; C282Y homozygosity in HFE gene was found in $85 \%$ patients with hemochromatosis (1). Marked iron overload can induce organ and tissue damage by producing oxidative stress related to the presence

\footnotetext{
${ }^{1}$ Department of Medicine, Aichi Gakuin University School of Pharmacy, Nagoya, ${ }^{2}$ Department of Clinical Medicine and Prevention, University of Milano-Bicocca, Italy, ${ }^{3}$ Division of Nephrology, Department of Internal Medicine, Kanazawa Medical University, Ishikawa, ${ }^{4}$ Divison of Gastroenterology, Department of Internal Medicine, Nagoya University School of Medicine, Nagoya, ${ }^{5}$ Department of Internal Medicine, Tamano Municipal Hospital, Okayama, ${ }^{6}$ Department of Medical Technology, Nagoya University School of Health Sciences, Nagoya and ${ }^{7}$ Department of Medicine, Yokkaichi City Hospital, Yokkaichi

Received for publication June 14, 2010; Accepted for publication August 20, 2010

Correspondence to Dr. Hisao Hayashi, hhayashi@dpc.agu.ac.jp
} 
of "free iron" or "labile iron". Accordingly, iron depletion by venesection is the standard treatment for patients with HFE-hemochromatosis. Treatment at the pre-fibrosis stage is essential because hepatocellular carcinoma can develop in patients with advanced liver fibrosis even after iron removal (2). Iron-induced oxidative stress in the liver can also be induced by chronic infection with hepatitis $\mathrm{C}$ virus (HCV) and some studies suggest that in patients with chronic hepatitis $\mathrm{C}(\mathrm{CHC})$, the coexistence of even a slight amount of excess iron in the liver may exacerbate this oxidative stress and promote liver injury and fibrosis, and in some cases, promote carcinogenesis $(3,4)$. Over the last 20 years, the treatment of choice for $\mathrm{CHC}$ has been interferon (IFN) therapy (5). Even though the clinical administration of pegylated IFN and combination therapy with ribavirin have improved the viral clearance rate, these antiviral therapies are effective in eradicating the virus in only approximately $50 \%$ of patients (6). Therefore, venesection has been proposed as an alternative in $\mathrm{CHC}$ patients who either were contraindicated or responded poorly to IFN therapy, but the routine application of venesection for the treatment of $\mathrm{CHC}$ patients remains limited worldwide.

Hepcidin, a peptide synthesized in the liver, is the main regulator of iron homeostasis by inhibiting intestinal iron absorption and iron release by macrophages $(7,8)$. Functionally, hepcidin secreted into the circulation binds to ferroportin, the only known cellular iron exporter, inducing its internalization and degradation (9). Thus, the downregulation of ferroportin controls iron efflux from enterocytes and reticuloendothelial cells into the circulation. Hemochromatosis proteins act as positive regulators of hepcidin. Thus, hepcidin synthesis is at a low level in patients with HFE-hemochromatosis, which is the primary explanation for the development of iron overload in these patients (10). Venesection further decreases serum and urinary hepcidin to very low levels in patients with HFEhemochromatosis, indicating that they are still able to modulate, although inappropriately, hepcidin production in response to iron stores $(11,12)$. Investigation of hepcidin regulation has been limited due to the lack of reliable methods. Recently serum hepcidin levels of $\mathrm{CHC}$ patients were measured in 2 studies using different methods $(13,14)$. Both studies indicated that hepcidin regulation by iron stores is maintained in $\mathrm{CHC}$ and suggested that $\mathrm{HCV}$ infection can impair hepcidin production, which may be an important factor in hepatic iron accumulation.

Based on previous data on the possible beneficial effect of venesection in HFE-hemochromatosis and CHC (2-4), we investigated iron-induced hepatotoxicity and hepcidin regulation under these iron overload conditions.

\section{Subjects and Methods}

Fourteen Japanese patients with CHC ( 8 males and 6 females; aged $57 \pm 8$ years) and eight Italians with HFEhemochromatosis (6 males and 2 females; aged $49 \pm 17$ years) were treated by venesection. Age-matched controls were selected from a database of healthy Japanese volunteers ( 8 males and 6 females; aged $56 \pm 7$ ). Inclusion criteria for $\mathrm{CHC}$ patients were: $\mathrm{HCV}$-positive chronic hepatitis, alcohol intake $<25 \mathrm{~g} /$ day, absence of coexisting hepatitis $\mathrm{B}$ virus (HBV) infections; absence of decompensated cirrhosis; absence of coexisting conditions that could influence iron parameters, such as acute and chronic inflammatory diseases and hematological disorders, venesection, iron supplementation or repeated transfusions. All CHC patients were either non-responders to IFN or had refused IFN therapy. Most patients were under long-term ursodeoxycholic acid treatment without interruption during venesection. Demographic information showing that the HFE mutant has an almost zero incidence among Japanese (15) permitted omission of HFE analysis in this population. Inclusion criteria for HFEhemochromatosis were increased transferrin saturation and serum ferritin, and homozygosity for $\mathrm{C} 282 \mathrm{Y}$ mutation in HFE (1). HBV, HCV or human immunodeficiency virus infections and high alcoholic intake were exclusion criteria for the hemochromatosis group. Patients with $\mathrm{CHC}$ received venesection with modified endpoints of serum ferritin of 20 $\mathrm{ng} / \mathrm{mL}$ or hemoglobin of $12.0 \mathrm{~g} / \mathrm{dL}$ based on a previous report (3) because iron deficiency anemia might decrease hepcidin production. A volume of $200 \mathrm{~mL}$ for female patients and $400 \mathrm{~mL}$ for male patients was removed every two weeks. Italian patients with HFE-hemochromatosis were treated by standard venesection with an endpoint of serum ferritin levels of less than $50 \mathrm{ng} / \mathrm{mL}$. A volume of $350 \mathrm{~mL}$ for female patients and $400 \mathrm{~mL}$ for male patients was drawn each week.

Routine laboratory tests included hemoglobin, serum alanine aminotransferase (ALT) activities, serum iron, total iron binding capacity and ferritin concentration. Transferrin saturation (TS) was calculated according to the standard method. Serum hepcidin 25 was quantified by liquid chromatography tandem mass spectrometry in the laboratory of Kanazawa Medical University, and expressed as $\mathrm{ng} / \mathrm{mL}$ as reported previously (16).

Because $\mathrm{Hb}$ did not change in venesection for hemochromatosis, body iron stores were simply estimated from the total iron removed using a modified version of the following formula reported previously (17) [mean $\mathrm{Hb}(\mathrm{g} / \mathrm{dL}) \times 0.034 \times$ total blood volume $(\mathrm{mL})]$. Body iron stores of hepatitis with post treatment anemia were adjusted by reduced hemoglobin $\mathrm{Hb}$ ) concentration during venesection: body iron stores $(\mathrm{mg})=$ total iron removed $(\mathrm{mg})$ - reduced blood iron $(\mathrm{mg})$ $[\Delta \mathrm{Hb}(\mathrm{g} / \mathrm{dL}) \times 0.034 \times 1 / 15 \times$ body weight $(\mathrm{g})] . \Delta \mathrm{Hb}(\mathrm{g} / \mathrm{dL})$ was defined as the change in the concentration after venesection.

Reduction of ALT activity was calculated as [pretreatment activity-post treatment activity]. Based on a hypothesis that sensitivity to iron-induced hepatotoxicity might be represented by a ratio of ALT reduction during venesection to body iron stores, the iron hepatotoxicity index (IHI) was calculated by [dividing reduction in ALT activity by body iron stores estimated from total volume of removed 
Table 1. Laboratory Data of Controls and Patients Receiving Venesection

\begin{tabular}{|c|c|c|c|c|c|c|}
\hline Subjects & $\begin{array}{l}\mathrm{Hb} \\
(\mathrm{g} / \mathrm{dL})\end{array}$ & $\begin{array}{l}\text { Hepcidin } \\
(\mathrm{ng} / \mathrm{mL})\end{array}$ & $\begin{array}{l}\text { Ferritin } \\
(\mathrm{ng} / \mathrm{mL})\end{array}$ & $\mathrm{H} / \mathrm{F}$ ratio & $\begin{array}{l}\text { TS } \\
(\%)\end{array}$ & $\begin{array}{l}\text { ALT } \\
(\mathrm{U} / \mathrm{L})\end{array}$ \\
\hline \multicolumn{7}{|l|}{ Japanese Control $(n=14)$} \\
\hline Base line & $14.0 \pm 1.4$ & $33.7 \pm 17.9$ & $110 \pm 81$ & $0.48 \pm 0.47$ & $35.8 \pm 9.3$ & $20 \pm 7$ \\
\hline \multicolumn{7}{|l|}{ Japanese CHC $(n=14)$} \\
\hline Pre Treatment & $14.6 \pm 1.1$ & $30.7 \pm 14.5$ & $250 \pm 132$ & $0.14 \pm 0.07$ & $45.3 \pm 12.9$ & $90 \pm 27$ \\
\hline Post Treatment & $13.1 \pm 1.3$ & $2.0 \pm 1.4$ & $15 \pm 4$ & $0.15 \pm 0.12$ & $17.2 \pm 5.7$ & $41 \pm 16$ \\
\hline pl (Pre vs. Cont) & ns & ns & $<0.01$ & 0.018 & 0.034 & $<0.01$ \\
\hline p4 (Pre vs. Post) & $<0.01$ & $<0.01$ & $<0.01$ & ns & $<0.01$ & $<0.01$ \\
\hline \multicolumn{7}{|c|}{ Italian Hemochromatosis $(\mathrm{n}=8)$} \\
\hline Pre Treament & $14.6 \pm 0.8$ & $11.1 \pm 9.2$ & $1347 \pm 620$ & $0.01 \pm 0.01$ & $83 \pm 14$ & $40 \pm 21$ \\
\hline Post Treatment & $14.8 \pm 0.5$ & $2.1 \pm 2.3$ & $49 \pm 16$ & $0.05 \pm 0.05$ & $41 \pm 13$ & $18 \pm 5$ \\
\hline pl (Pre vs. Control) & ns & $<0.01$ & $<0.01$ & $<0.01$ & $<0.01$ & ns \\
\hline$p 2$ (Pre vs. Pre CHC) & ns & $<0.01$ & $<0.01$ & $<0.01$ & $<0.01$ & $<0.01$ \\
\hline p3 (Post vs. Post CHC) & $<0.01$ & ns & $<0.01$ & 0.012 & $<0.01$ & $<0.01$ \\
\hline$p 4$ (Pre vs. Post) & ns & 0.014 & $<0.01$ & ns & $<0.01$ & 0.016 \\
\hline
\end{tabular}

H/F; hepcidn/ferritin, ALT; alanine aminotransferase, TS; transferrin saturation, CHC; chronic hepatitis C, p1; statistical analysis of pre-treatment values compared to control baseline, $p 2$; statistical analysis of pre-treatment values compared to those of $\mathrm{CHC}$, $p 3$; statistical analysis of post treatment values compared to those of $\mathrm{CHC}, p 4$; statistical analysis of pre-treatment and post-treatment values.

There were sex differences in $\mathrm{Hb}$ and serum ferritin concentration, but not in serum levels of hepcidin and ALT in controls.

Pre-treatment patients with hemochromatosis were characterized by remarkably high levels of ferritin and transferrin saturation, and low levels of hepcidin and ALT compared to those with CHC. Baseline levels of hepcidin did not differ between controls and CHC, but the hepcidin/ferritin ratio, an iron regulatory hormone index adjusted by representative values of body iron stores, were low in $\mathrm{CHC}$. Regardless of the different endpoints, both patients with $\mathrm{CHC}$ and those with hemochromatosis responded similarly to venesection treatment. Post treatment levels of hepcidin were quite low in all patients regardless of CHC or hemochromatosis.

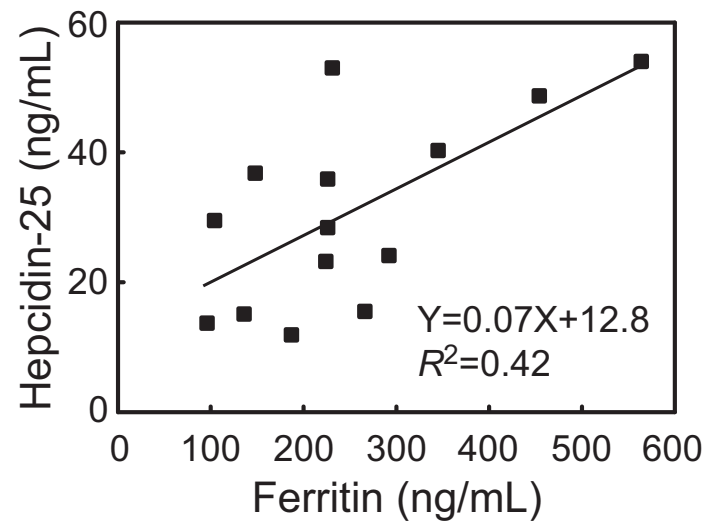

Figure 1. A correlation between serum levels of ferritin and hepcidin 25 in pre-treatment patients with chronic hepatitis $\mathbf{C}$. Hepcidin might regulate iron homeostasis in chronic hepatitis C patients.

blood].

These procedures including venesection were performed in accordance with guidelines for Human Research at Nagoya University Hospital and Milano-Bicocca University. For statistical analysis, biochemical indices were expressed as mean $\pm \mathrm{SD}$, and differences between pre- and posttreatment values, and those among patient groups were analyzed using Student's t test. Gender differences were not considered in the study because of the small number of patients.

\section{Results}

Laboratory data of subjects at entry and post-venesection are summarized in Table 1. Pre-treatment levels of serum ferritin, transferrin saturation and ALT differed among groups. Serum ferritin levels and TS were markedly elevated in hemochromatosis, and slightly increased in CHC compared to those in controls. ALT levels were three times higher than the upper normal value in patients with $\mathrm{CHC}$ and only slightly increased in hemochromatosis patients. Pre-treatment hepcidin levels of hepatitis patients did not significantly differ compared with those of controls (33.7 \pm 17.9 vs. $30.7 \pm 14.5 \mathrm{ng} / \mathrm{mL}, \mathrm{p}=0.64)$, but the hepcidin/ferritin ratio in hepatitis patients was significantly lower than that in controls $(0.14 \pm 0.07$ vs. $0.48 \pm 0.47, \mathrm{p}=0.018)$. Serum hepcidin levels were significantly lower in patients with hemochromatosis. Markedly low levels of hepcidin and high levels of ferritin induced quite low values for the hepcidin index in hemochromatosis patients. A significant correlation was observed in the pre-treatment levels between serum hepcidin and ferritin in CHC patients ( $\mathrm{r}=0.65, \mathrm{p}=0.012)$ (Fig. 1), but not in controls and hemochromatosis patients (data not shown). The small number of controls and patients 


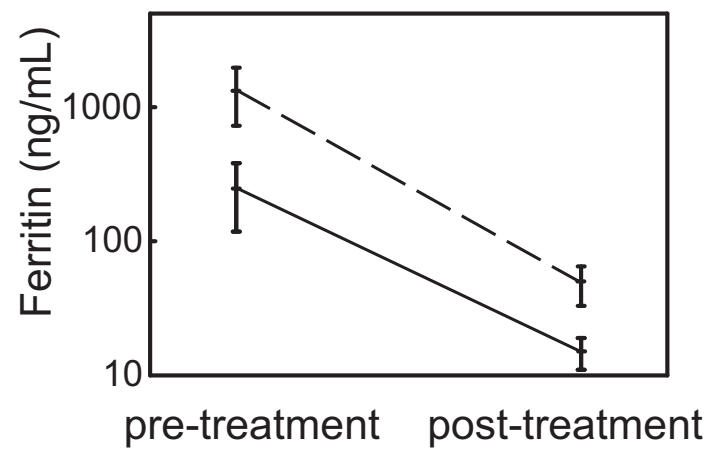

Figure 2. Reduction of serum ferritin levels in the 2 patient groups by venesection. Note that the endpoints were set differently: $20 \mathrm{ng} / \mathrm{mL}$ for chronic hepatitis $\mathrm{C}$ (a straight line), and $50 \mathrm{ng} / \mathrm{mL}$ for HFE-hemochromatosis (a dotted line). High starting points of $1347 \pm 620 \mathrm{ng} / \mathrm{mL}$ in hemochromatosis patients indicate severe iron overload in the genetic disorder as compared to those of $250 \pm 132 \mathrm{ng} / \mathrm{mL}$ in chronic hepatitis $\mathrm{C}$ patients. Vertical bars indicate mean \pm SD.

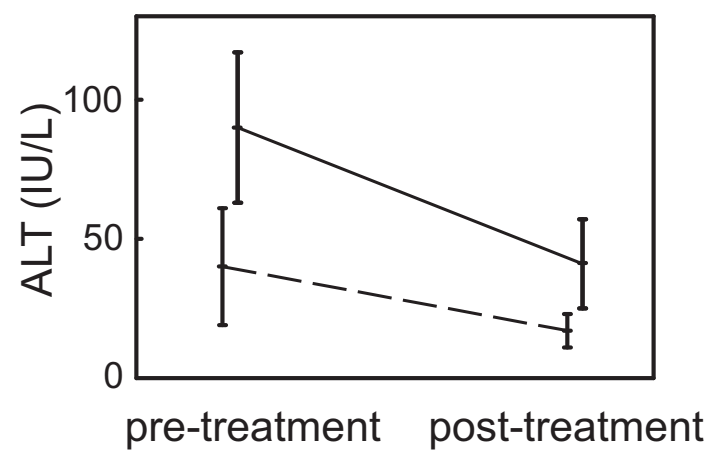

Figure 3. Reduction of serum ALT levels in the 2 patient groups by venesection. The parameter of biochemical liver disease was normalized in HFE-hemochromatosis (dotted line), but remained slightly elevated in chronic hepatitis $\mathrm{C}$ (straight line), suggesting that viral insult persisted after iron hepatotoxicity was removed. ALT; alanine aminotransferase. Vertical bars indicate mean \pm SD.

with HFE-hemochromatosis might have caused a false negative result.

There were no side effects of venesection requiring discontinuation of therapy. Hemoglobin concentration remained normal during venesection in hemochromatosis patients but decreased slightly in $\mathrm{CHC}$ patients. The serum ferritin concentrations used for monitoring body iron stores decreased linearly from $250 \pm 32 \mathrm{ng} / \mathrm{mL}$ to levels of $<20 \mathrm{ng} / \mathrm{mL}$ in $\mathrm{CHC}$, and from $1,347 \pm 620 \mathrm{ng} / \mathrm{mL}$ to levels $<50 \mathrm{ng} / \mathrm{mL}$ in hemochromatosis (Fig. 2). The treatment effectively reduced ALT to only slightly increased levels in CHC, and normalized these levels in hemochromatosis (Fig. 3). One exceptional patient with hemochromatosis showed an increase in the liver enzyme level from 15 to $23 \mathrm{U} / \mathrm{L}$. Serum hepcidin was significantly decreased in both $\mathrm{CHC}$ and hemochromatosis reaching comparable levels after iron depletion $(2.1 \pm$ $2.3 \mathrm{ng} / \mathrm{mL}$ in hemochromatosis vs. $2.0 \pm 1.4 \mathrm{ng} / \mathrm{mL}$ in

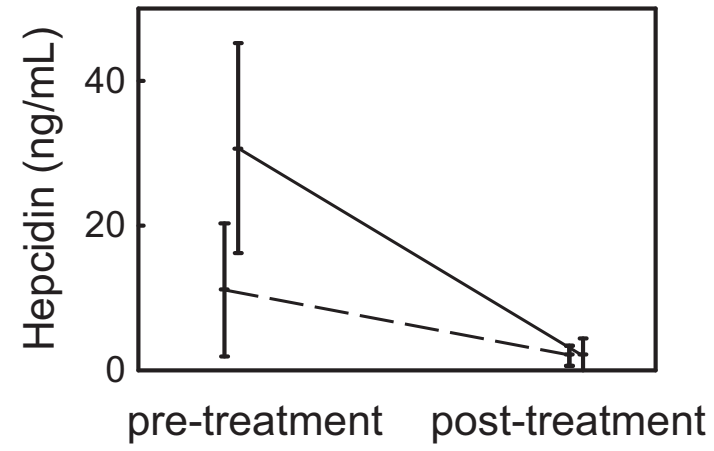

Figure 4. Reduction of serum hepcidin levels in the 2 patient groups by venesection. Serum hepcidin 25 levels of chronic hepatitis $\mathbf{C}$ (straight line) were similar to those of controls at the pre-treatment stage, while those of HFE-hemochromatosis (dotted line) were low at $11.1 \pm 9.2 \mathrm{ng} / \mathrm{mL}$. In both patient groups, hepcidin levels were reduced to quite low levels after venesection. It is clear that the hepcidin system is set at lower levels in HFE-hemochromatosis than in chronic hepatitis $\mathbf{C}$. Genetic setting with low hepcidin regulation caused a large amount of iron absorption in the intestine over 50 years. Vertical bars indicate mean \pm SD.

CHC) (Fig. 4). One exceptional patient with hemochromatosis showed an increase in serum hepcidin from 3.5 to 7.7 $\mathrm{ng} / \mathrm{mL}$.

The regimens and effects of venesection for patients with $\mathrm{CHC}$ and hemochromatosis are summarized in Table 2. Estimated body iron stores of $730 \pm 560 \mathrm{mg}$ were removed from hepatitis patients over $7 \pm 3$ months, while 5,960 \pm $2,750 \mathrm{mg}$ were removed from hemochromatosis patients over $15 \pm 8$ months. There were differences in the body iron stores and treatment periods between the 2 patient groups. In CHC patients, reduction of ALT activity by venesection was larger than that in hemochromatosis patients $(49 \pm 30$ vs. $22 \pm 20 \mathrm{U} / \mathrm{L}$ ). There were correlations between the reduction in ALT activity and pre-treatment ALT activity in both patient groups (Fig. 5, 6). IHI was quite low in hemochromatosis with a significant difference between the 2 patient groups $(0.097 \pm 0.083$ in $\mathrm{CHC}$ vs. $0.0032 \pm 0.0046 \mathrm{U} /$ $\mathrm{L} / \mathrm{mg}$ in hemochromatosis).

\section{Discussion}

In the present paper, we compared the behavior of serum iron indices including hepcidin-25 and liver enzymes in $\mathrm{CHC}$ and HFE-hemochromatosis during the first stage of venesection to remove body iron stores. Since, in addition to genetic background, dietary customs between Italians and Japanese, and the venesection protocols used for $\mathrm{CHC}$ and hemochromatosis are different, this comparative study may involve confounding factors. However, most of the findings observed are potentially significant. Considering that both conditions responded to venesection, iron hepatotoxicity is involved in their pathogenesis, but these iron disorders substantially differ with regard to mechanisms and amounts of 
Table 2. Regimens and Effects of Venesection Treatment in Chronic Hepatitis C and HFE-Hemochromatosis

\begin{tabular}{llll}
\hline & CHC & Hemochromatosis & $\begin{array}{l}\text { Statistical } \\
\text { Analysis }\end{array}$ \\
& & & 0.03 \\
Treatment Periods (months) & $7 \pm 3$ & $15 \pm 8$ & $<0.01$ \\
& & & $12,000 \pm 5,560$ \\
$\begin{array}{l}\text { Blood Volume Removed (mL) } \\
\text { Iron Removed by Venesection. (mg) }\end{array}$ & $940 \pm 550$ & $\begin{array}{l}5,960 \pm 2,750 \\
\text { negligible }\end{array}$ & $<0.01$ \\
$\begin{array}{l}\text { Iron in Reduced Hb (mg) } \\
\text { Body Iron Stores (mg) }\end{array}$ & $210 \pm 150$ & $5,960 \pm 2,750$ & $<0.01$ \\
ALT Reduction (U/L) & $730 \pm 560$ & $22 \pm 20$ & 0.02 \\
Iron Hepatotoxicity Index & $0.097 \pm 0.083$ & $0.0032 \pm 0.0046$ & $<0.01$ \\
\hline
\end{tabular}

CHC; chronic hepatitis C, ALT; alanine aminotransferase.

Treatment methods for $\mathrm{CHC}$ and hemochromatosis are different so that statistical analysis is not fully reliable. Body iron stores were calculated from the blood volume removed according to the formula described in the text. Iron hepatotoxicity index (IHI) was calculated by dividing reduction in ALT by body iron stores. Provided that iron-induced hepatotoxicity is represented by ALT reduction during iron removal treatment, IHI might be a sensitivity to iron hepatotoxicity. A high IHI in CHC suggests not only a high sensitivity to iron hepatotoxicity, but also a good benefit of iron removal treatment. In contrast, liver cells with HFE-mutation are highly tolerant of iron hepatotoxicity. Treatment regimens for hemochromatosis were stronger but effects were smaller than those for $\mathrm{CHC}$.

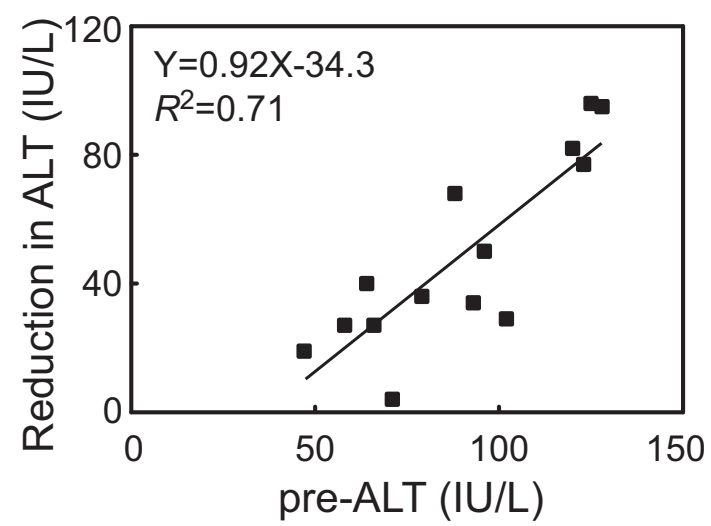

Figure 5. A good correlation between the reduction of ALT and pre-treatment ALT in chronic hepatitis C. Pre-treatment ALT level is predictive of efficacy by venesection. It may be important that other parameters including ferritin concentration are not predictive of treatment effects. In other words, the higher ALT is, the greater the treatment effect will be. ALT: alanine aminotransferase.

iron overload. In HFE-hemochromatosis, iron accumulates due to HFE-dependent derangement of hepcidin production $(10,11)$. Serum hepcidin-25 levels in our Italian HFEhemochromatosis patients were low at $11.1 \pm 9.2 \mathrm{ng} / \mathrm{mL}$. The current observations of circulating hepcidin 25 confirmed the findings previously observed in urine from patients with HFE-hemochromatosis (12). Low levels of serum hepcidin 25 were also found in Japanese patients with nonHFE hemochromatosis (18).

In $\mathrm{CHC}$ patients, the mechanism of hepatic iron accumulation appears to be more complex and is still not com-

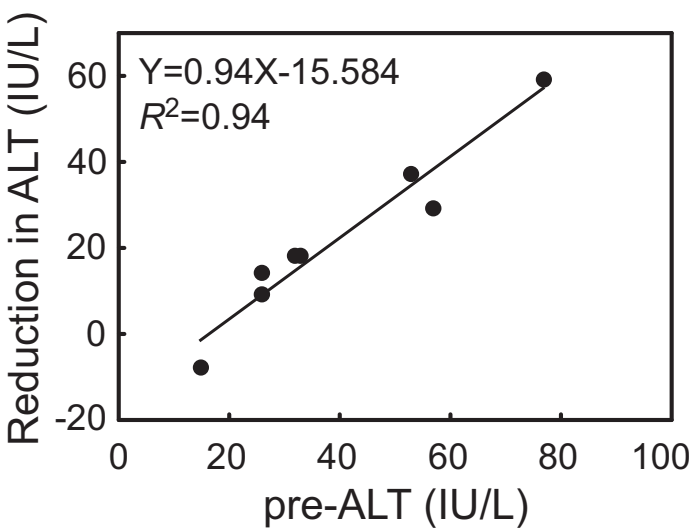

Figure 6. A good correlation between the reduction of ALT and pre-treatment ALT in HFE-hemochromatosis. Seven of 8 patients treated showed decreased serum ALT activities, while one of them had increased enzyme activity from 15 to $23 \mathrm{U} / \mathrm{L}$ after iron removal. It may be important that even though the levels are low, the effect of iron removal is ALT-dependent and not ferritin-dependent even in patients with HFE-hemochromatosis. ALT reduction may be the primary effect, and suppression of hepatic fibrosis might be a secondary event of venesection in both chronic hepatitis $\mathrm{C}$ and HFE-hemochromatosis. ALT: alanine aminotransferase.

pletely understood. Iron regulation by hepcidin might be partially impaired in CHC. Serum hepcidin-25 levels in our Japanese patients were relatively high at $30.7 \pm 14.5 \mathrm{ng} / \mathrm{mL}$ compared to those in Italian HFE-hemochromatosis patients. Our findings, including the reduced hepcidin/ferritin ratio and correlation between hepcidin and ferritin concentrations fit well with reports showing that hepcidin induction was 
relatively impaired in $\mathrm{CHC}$ patients, but also that its regulation by iron stores was maintained $(13,14)$. These findings are also in agreement with recent studies in animal and cellular models suggesting that HCV suppresses hepcidin production and may contribute to the development of iron overload in CHC $(19,20)$.

Previous study reported that none of the iron indices were predictive of the venesection effect, but rather the pretreatment ALT activities were predictive in CHC (21). The present study confirmed that this is also likely in HFEhemochromatosis. The pretreatment ALT was higher, the reduction in ALT was larger in both $\mathrm{CHC}$ and HFEhemochromatosis. Active liver cell damage could be removed by venesection regardless of the amount of stored iron. HCV co-infection in hemochromatosis patients markedly increases the risk of cirrhosis in the presence of a relatively low amount of iron (22). Therefore, with or without HCV infection, venesection should be recommended for HFE-hemochromatosis patients not only to remove excess iron, but also to suppress biochemical liver damage as in CHC patients. Provided that iron-induced hepatotoxicity is represented by ALT reduction during venesection, IHI obtained by [dividing ALT reduction by body iron stores] might be representative of sensitivity to iron hepatotoxicity under disease conditions. The IHI suggests not only sensitivity to iron hepatotoxicity, but also beneficial effects of venesection. CHC patients with a high IHI may be more sensitive to iron-induced liver damage than patients with HFEhemochromatosis with low IHI. Therefore, liver cells with HFE-mutation are more tolerant to iron hepatotoxicity than liver cells infected by HCV.

In HFE-hemochromatosis patients, iron accumulates slowly and redox active iron emerges only when the storage capacity for ferritin and hemosiderin is overwhelmed. In other words, because of the high tolerance to iron hepatotoxicity, clinical manifestation might be delayed in HFEhemochromatosis. The mean amount of iron removed from HFE hemochromatosis was reported to be $4.98 \mathrm{~g}$ (3.9-6.1 $\mathrm{g}$ in the range) (12), while that of $\mathrm{CHC}$ was $0.61 \mathrm{~g} \mathrm{(0-1.6} \mathrm{g}$ in the range) (17). The results of the current study did not differ from those in the literature. It is also important that the amount of body iron in CHC patients is considered a nontoxic level in healthy subjects because sensitivity to iron hepatotoxicity disappeared in complete responders to IFN without iron removal (13). However, the combination of even a slightly increased iron level with HCV-related insult may act synergistically to increase iron hepatotoxicity and the risk of progressive liver damage so that iron removal can be beneficial in this setting $(3,4)$.

Patients with HFE-hemochromatosis showed normalized serum ALT activity after venesection, while all CHC patients showed significantly reduced but not normalized activity on biochemical liver function test. Iron hepatotoxicity was totally removed from HFE-hemochromatosis at $50 \mathrm{ng} /$ $\mathrm{mL}$ of serum ferritin, while it remained in $\mathrm{CHC}$ around 20 $\mathrm{ng} / \mathrm{mL}$ serum ferritin. The modified endpoint of 20 from 10 $\mathrm{ng} / \mathrm{mL}$ for $\mathrm{CHC}$ still induced a reduction of $\mathrm{Hb}$ concentration in the posttreatment period $(1.6 \pm 1.1 \mathrm{~g} / \mathrm{dL})$. This incomplete effect of venesection in $\mathrm{CHC}$ indicates at least 2 compartments of hetatotoxicity of iron-induced oxidative stress and HCV-dependent insult. $\mathrm{Hb}$ concentration did not change in HFE-hemochromatosis with a high serum ferritin endpoint of $50 \mathrm{ng} / \mathrm{mL}$. The high endpoint for HFEhemochromatosis may account for the good tolerance to venesection to remove large amounts of body iron stores. Thus, threshold and sensitivity for iron hepatotoxicity were apparently different under the 2 conditions.

The remarkable reduction in serum hepcidin levels after venesection for iron overload conditions indicates suppressed internalization of ferroportin to enhance iron absorption in the gut. Thus, patients will rapidly recover iron stores if receiving a normal diet. Based on those findings, low-iron diets may be recommended to reduce active iron absorption in the intestine during the second stage of venesection in order to maintain free from iron-induced hepatotoxicity in Japanese patients with $\mathrm{CHC}(4,23)$. In HFEhemochromatosis with good tolerance to venesection, the effect of dietary iron restriction might be negligible.

To summarize an iron-induced hepatotoxicity under these 2 disease conditions, CHC patients were loaded with a minimum iron burden, but were more sensitive to iron-induced hepatotoxicity and less tolerant of venesection. In contrast, HFE-hemochromatosis patients were loaded with excessive iron due to genetic dysregulation of the hepcidin system and were more tolerant to both iron-induced hepatotoxicity and venesection to remove large amounts of body iron stores.

\section{References}

1. Feder JN, Gnirke A, Thomas W, et al. A novel MHC class 1-like gene is mutated in patients with hereditary haemochromatosis. Nat Genet 13: 399-408, 1996.

2. Alexander J, Kowdley KV. HFE-associated hereditary hemochromatosis. Genet Med 11: 307-313, 2009.

3. Hayashi H, Takikawa T, Nishimura N, et al. Improvement of serum aminotransferase levels after phlebotomy in patients with chronic hepatitis $\mathrm{C}$ and excess hepatic iron. Am J Gastroenterol 89: 986-988, 1994.

4. Kato J, Kobune M, Nakamura T, et al. Normalization of elevated hepatic 8-hydroxy-2'-deoxyguanosine levels in chronic hepatitis C patients by phlebotomy and low iron diet. Cancer Res 61: 86978702, 2001.

5. Hoofnagle JH, Seeff LB. Peginterferon and ribavirin for chronic hepatitis C. N Engl J Med 355: 2444-2451, 2006.

6. Younossi Z, Kallman J, Kincaid J. The effects of HCV infection and management on health-related quality of life. Hepatology 45: 806-816, 2007.

7. Nicolas G, Bennoun M, Devaux I, et al. Lack of hepcidin gene expression and severe tissue iron overload in upstream stimulatory factor 2 (USF2) knockout mice. Proc Natl Acad Sci USA 98: 8780-8785, 2001.

8. Pigeon C, Ilyin G, Courselaud B, et al. A new mouse liverspecific gene, encoding a protein homologous to human antimicrobial peptide hepcidin, is overexpressed during iron overload. J Biol Chem 276: 7811-7819, 2001.

9. Nemeth E, Tuttle MS, Powelson J, et al. Hepcidin regulates cellular iron efflux by binding to ferroportin and inducing its internali- 
zation. Science 306: 2090-2093, 2004

10. Bridle KR, Frazer DM, Wilkins SJ, et al. Disrupted hepcidin regulation in HFE-associated haemochromatosis and the liver as a regulator of body iron homeostasis. Lancet 361: 669-673, 2003.

11. van Dijk BAC, Laarakkers CM, Klaver SM, et al. Serum hepcidin levels are innately low in HFE-related haemochromatosis but differ between C282Y-homozygotes with elevated and normal ferritin levels. Br J Haematol 142: 979-985, 2008.

12. Piperno A, Girelli D, Nemeth E, et al. Blunted hepcidin response to oral iron challenge in HFE-related hemochromatosis. Blood 110: 4096-4100, 2007.

13. Fujita N, Sugimoto R, Motonichi S, et al. Patients with chronic hepatitis $\mathrm{C}$ achieving a sustained virological response to peginterferon and ribavirin therapy recover from impaired hepcidin secretion. J Hepatol 49: 702-710, 2008.

14. Girelli D, Pasino M, Goodnough JB, et al. Reduced serum hepcidin levels in patients with chronic hepatitis C. J Hepatol 51: 845-852, 2009.

15. Sohda T, Yanai J, Soejima H, Tamura K. Frequencies in the Japanese populations of the HFE gene. Biochem Genet 37: 63-68, 1999.

16. Murao N, Ishigai M, Yasuno H, et al. Simple and sensitive quantification of bioactive peptides in biological matrices using liquid chromatography/selected reaction monitoring mass spectrometry coupled with trichloroacetic acid clean-up. Rapid Commun Mass
Spectrom 21: 4033-4038, 2007.

17. Shiono $\mathrm{Y}$, Hayashi $\mathrm{H}$, Wakusawa $\mathrm{S}$, et al. Iron stores and iron restoration rate in Japanese patients with chronic hepatitis $\mathrm{C}$ as measured during therapeutic iron removal revealed neither increased iron stores nor effects of $\mathrm{C} 282 \mathrm{Y}$ and H63D mutations on iron indices. Nagoya J Med Sci 64: 51-57, 2001.

18. Kaneko Y, Miyajima H, Peperno A, et al. Measurement of serum hepcidin-25 levels as a potential test for diagnosing hemochromatosis and related disorders. J Gastroenterol 2010 Jun 9 [Epub ahead of print].

19. Nishina $S$, Hino $K$, Korenaga $M$, et al. Hepatitis $C$ virus-induced reactive oxygen species raise hepatic iron level in mice by reducing hepcidin transcription. Gastroenterology 134: 226-238, 2008.

20. Miura K, Taura K, Kodama $Y$, et al. Hepatitis $C$ virus-induced oxidative stress suppresses hepcidin expression through increased histone deacetylase activity. Hepatology 48: 1420-1429, 2008.

21. Hayashi H, Takikawa T, Nishimura N, et al. Serum aminotransferase levels as an indicator of the effectiveness of venesection for chronic hepatitis C. J Hepatol 22: 268-271, 2005.

22. Piperno A, Fargion S, D'Alba R, et al. Liver damage in Italian patients with hereditary hemochromatosis is highly influenced by hepatitis B and C virus infection. J Hepatol 16: 364-368, 1992.

23. Kimura F, Hayashi H, Yano M, et al. Additional effect of low iron diet on iron reduction therapy by phlebotomy for chronic hepatitis C. Hepatogastroenterology 52: 563-566, 2005.

(C) 2010 The Japanese Society of Internal Medicine

http://www.naika.or.jp/imindex.html 